\title{
Rapid adenovirus typing by immunoelectron microscopy
}

\author{
P. LUTON
}

From the Department of Microbiology, University College Hospital, London

SYNOPSIS A rapid method of typing adenoviruses by immunoelectron microscopy is described This emphasizes the value of an electron microscope in diagnostic virology, especially when a rapid result is required in epidemiology.

If virological diagnosis is to be of practical value, speed in reporting is essential and methods employing electron microscopy are being investigated with this end in view. Although specific antiviral treatment is lacking for most infections at present a rapid report is of practical use in epidemiology, and also in warning the clinician that antibacterial chemotherapy is contraindicated.

The electron microscope has been used since the early 1960 s for the differentiation of smallpox and chickenpox by the examination of negatively stained material from lesions. More recently, immunoelectron microscopy has been developed to make the electron microscope a more useful diagnostic tool.

Immunoelectron microscopy is a rapid, sensitive technique enabling the direct observation of virusantibody complexes and has been used for a number of purposes. This technique enabled Best, Banatvala, Almeida, and Waterson (1967) to take the first conclusive pictures of rubella virus. Immunoelectron microscopy has been of value in the diagnosis of serum hepatitis and has also been used to study virus-antibody interactions in a number of viruses infecting human beings, including poliovirus (Hummeler, Anderson, and Brown, 1962), influenza (Lafferty and Oertelis, 1963), herpes simplex (Rigby and Johnson, 1972), and rhinovirus(Kapikian, Almeida, and Scott, 1972).

In the routine bacteriology laboratory, agglutination methods are used to type strains of different organisms, and, since using immunoelectron microscopy it is possible to visualize agglutinated viruses, it was decided to use the technique to type adenoviruses.

Adenoviruses are commonly isolated and easily distinguished in the electron microscope. A rapid Received for publication 20 September 1973. typing method would be valuable, especially in the recognition of transfer of viruses betweenpatients. No previous account in the literature of and immunoelectron microscopic typing method for thiso virus could be found. Most of the strains typed were 3 isolated in our own laboratory but a number were므. kindly sent to us from St Mary's Hospital, Padding $\vec{\varphi}$ ton.

The typings of these viruses were confirmed neutralization in tissue culture.

\section{Materials and Methods}

TISSUE CULTURE

The adenoviruses were propagated in $\mathrm{HeP}_{2}$ cell $\overrightarrow{\bar{F}}$ monolayers in 6 in $\times \frac{5}{8}$ in glass tubes. The cells were 3 fed on Eagles MEM plus $10 \%$ foetal calf serum, $1 \%$ glutamine, $1 \%$ glucose, and containing 500 units penicillin, $200 \mu \mathrm{g}$ streptomycin, and $2.5 \mu \mathrm{g}$ ampho-응 tericin B per ml.

\section{VIRUS}

The strains of adenovirus were isolated from swabs from patients with suspected virus infections and were identified by their characteristic cytopathic effect in tissue culture. The culture tubes containing the virus were frozen and thawed once, and $0.2 \mathrm{ml}$, of this suspension was inoculated into each of five $N$ other culture tubes. These tubes were incubated at $t_{N}$ $37^{\circ} \mathrm{C}$ and examined daily for their cytopathic effect. 은 When there was at least $75 \%$ cytopathic effect in the ${ }^{\omega}$ tubes, the cells were scraped from the walls of three of the tubes and the cell suspensions were combinede and centrifuged at $1500 \mathrm{rpm}$ in an MSE bench centrifuge for 15 minutes. The supernatant medium was decanted and $0.8 \mathrm{ml}$ distilled water was added ${ }^{-}$ to the cell pellet with shaking until lysis occurred. This suspension could then be used immediately for 
immunoelectron microscopy or clarified by lowspeed centrifugation before use if too much cell debris remained suspended.

The other two infected tubes were used for neutralization tests, and were frozen and thawed once. The resulting suspension diluted 1:10 with Earles B.S.S. containing lactalbumin hydrolysate (ELa) was used as the inoculum for these tests.

\section{ANTISERA}

The antisera used for immunoelectron microscopy and neutralization tests were the adenovirus neutralizing antisera supplied by theStandards Laboratory ${ }^{1}$. The groups I and II polyvalent pools containing antibodies to types $1,2,5$, and 6 , and types $3,4,7$, and 14 respectively were used for group typing. Final identification was made with the individual antisera. All were used at their recommended concentrations for neutralization tests and at 10 times this concentration for immunoelectron microscopy.

\section{NEUTRALIZATION}

Equal volumes $(0 \cdot 2 \mathrm{ml})$ of diluted virus suspension and antiserum were mixed in 2 in $\times \frac{1}{2}$ in glass tubes and incubated for an hour at $37^{\circ} \mathrm{C}$. Positive and negative (uninoculated) controls were tested in parallel with the unknown strains. After incubation, $0.2 \mathrm{ml}$ aliquots from each tube were inoculated onto $\mathrm{HeP}_{2}$ monolayers using two tubes per test. The culture tubes were then incubated at $37^{\circ} \mathrm{C}$ and examined daily for their cytopathic effect. A positive result was indicated by the serum which inhibited the production of a cytopathic effect for two days compared with the positive control. The virus was first tested against the two polyvalent pools, and then against the individual antisera from its particular group. Typing by this method takes on average 10-12 days and involves the use of 20 culture tubes per strain.

\section{IMMUNOELECTRON MICROSCOPY}

For immunoelectron microscopy, $0 \cdot 1 \mathrm{ml}$ of virus suspension obtained by lysis of the infected cells was mixed with $0.1 \mathrm{ml}$ of antiserum and incubated at $37^{\circ} \mathrm{C}$ for one hour. A control was incubated with phosphate-buffered saline. Again the virus was tested first against the antisera pools and then against the individual antisera.

After incubation, one drop of the test suspension was mixed with one drop of phosphotungstic acid ( $3 \%$ aqueous, $\mathrm{pH} 6 \cdot 8)$ on a microscope slide, and one drop of this mixture was placed onto the surface of a carbon-formvar coated 400 mesh copper grid held in fine pointed forceps. After a few seconds the excess

IStandards Laboratory, Central Public Health Laboratory, Colindale, London NW9. liquid was drained off by touching a piece of filter paper to the edge of the grid. The grids were then allowed to dry and were examined in a Hitachi HS-8 electron microscope at an instrument magnification of $31000 \times$.

Typing by this method takes only four to five hours and requires only three culture tubes.

\section{Results}

Electron microscopic examination of the grids prepared from controls showed normal adenovirus particles surrounded by the dark ring of phosphotungstic acid (PTA) stain (fig 1). When observed in the electron microscope a positive result was indicated by the presence of large aggregates of virus particles surrounded by a diffuse dark zone (fig 3 ). A negative result appeared exactly the same as the control, ie, virus particles usually singly but sometimes in groups of two or three surrounded by a definite dark ring of stain (fig 2).

It was also noted that when photographed virions in aggregates (fig 3) were less distinct in outline than individual particles in the negative tests or controls (figs 1 and 2), presumably due to the attached antibody.

Thirty-five strains isolated in our own laboratory and nine strains from St Mary's hospital were typed both by neutralization and by immunoelectron microscopy; the results of these typings are shown in the table. All typings were confirmed by neutralization tests; the strains from St Mary's hospital were

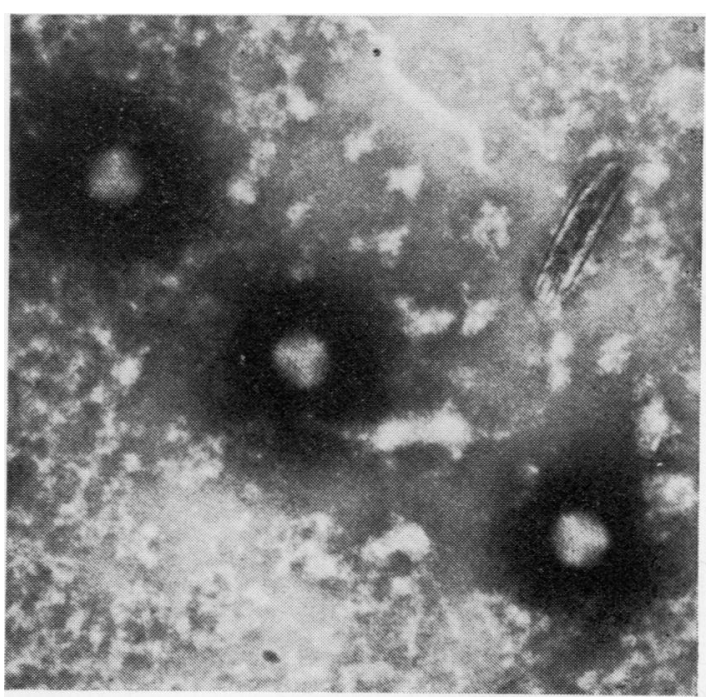

Fig 1 Adenovirus type $3+$ P.B.S. (Control) $\times 90000$ PTA stain 


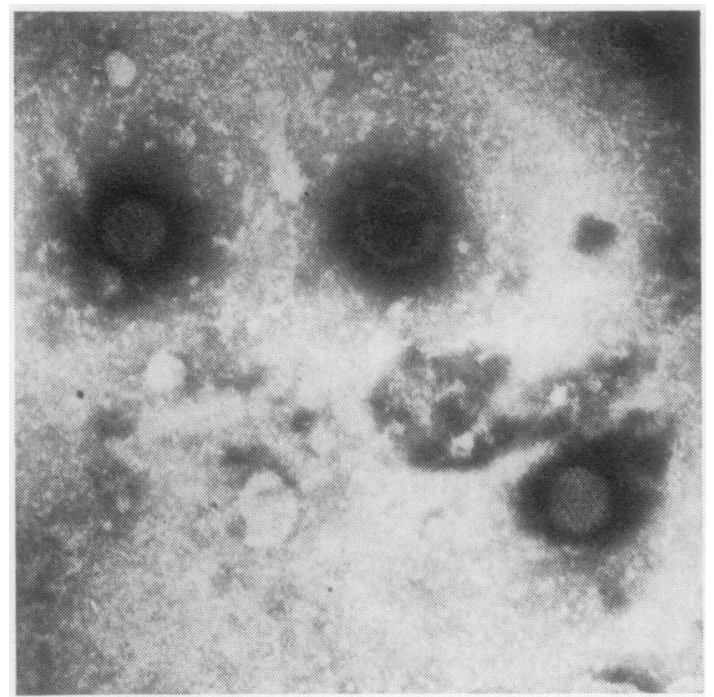

Fig 2 Adenovirus type $3+$ type 7 antiserum $\times 90000$ PTA stain

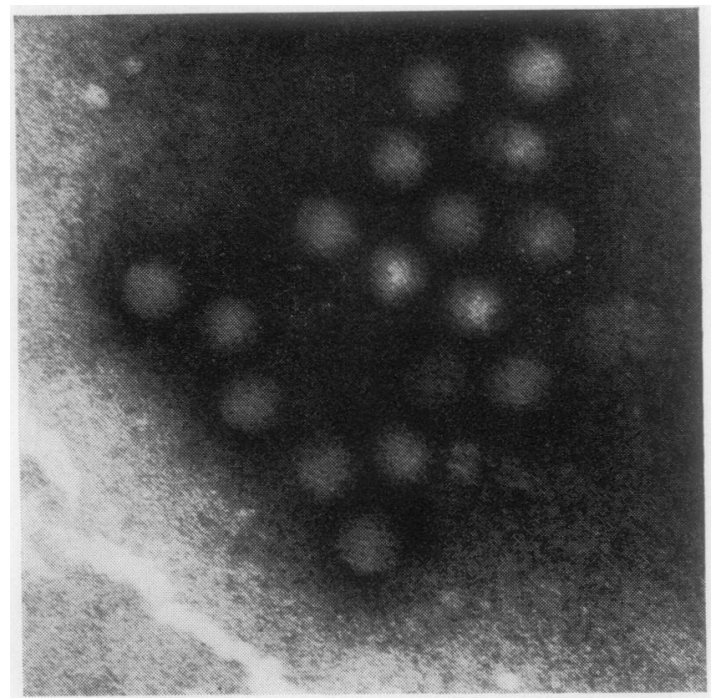

Fig 3 Adenovirus type $3+$ type 3 antiserum $\times 90000$ PTA stain

\begin{tabular}{lllllllll}
\hline No. of Strains Typed & Group I Types & \multicolumn{3}{c}{ Group } & II Types \\
& 1 & 2 & 5 & 6 & 3 & 4 & 7 & 14 \\
\hline
\end{tabular}

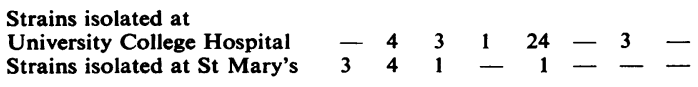

Table Adenoviruses typed by immunoelectron microscopy

All the strains typed by immunoelectron microscopy were confirmed by neutralization tests. typed independently at their own virology labora- $\frac{\text { 宁 }}{\underline{0}}$ tory. One of the type 7 adenoviruses required three $\overrightarrow{\vec{F}}$ attempts before it was satisfactorally typed by immunoelectron microscopy but even so it required을 only six culture tubes and took six days.

\section{Discussion}

The method of immunoelectron microscopy typing $\vec{P}$

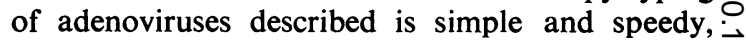
reducing the time required for typing after initial $\vec{\omega}$ isolation from 10 to 12 days to four to five hours. The number of culture tubes required in typing each strain was reduced from 20 to three, leaving more tubes for further isolations. The results obtained by this method compare favourably with? typing by neutralization as performed in our own laboratory and at St Mary's Hospital virology laboratory.

Apart from saving time and materials, another $\vec{\square}$ advantage is that, provided the virus is harvested ${ }^{\infty}$ when there is at least $75 \%$ cytopathic effect, there $\stackrel{\oplus}{7}$ will be sufficient virus present in the fluid from the 0 lysed cells to perform the typing without need for $\stackrel{\mathbb{C}}{-}$ further concentration; occasionally the suspensien $\overrightarrow{0}$ may have to be diluted to give a clear result. The $\omega$ technique has been useful in the diagnosis of a smal' outbreak of adenovirus infection in the childrens ward and the neonatal unit in this hospital during 1972. The infection was characterized by fever, vomiting, and diarrhoea lasting for about two days. $\frac{\circ}{\mathbb{Q}}$ Throat swabs and/or rectal swabs or faeces were $\stackrel{\varrho}{\rightarrow}$ taken from five infected children. In all cases, $\overrightarrow{\overrightarrow{0}}$ adenovirus was isolated. Immunoelectron microscopy showed them all to be of type 3 , and the results were later confirmed by neutralization tests.

By conventional techniques, the time taken to용 obtain a result greatly reduces the value of diagnostic:virology. This technique demonstrates the value of 3 . an electron microscope both in speed of results and in economizing on tissue culture materials.

I should like to thank Dr D. Jeffries of St Mary's Hospital, Paddington, for supplying adenovirus specimens, and Dr E. J. Stokes and Professor G. N Belyavin for their help and encouragement in the preparation of this manuscript.

References

Best, J. M., Banatvala, J. E., Almeida, J. D., and Waterson, A. P. (1967). Morphological characteristics of rubella virus. Lancet, 2, 237-239.

Hummerler, K., Anderson, T. F., and Brown, R. A. (1962). Identification of poliovirus particles of different antigenicity by우 specific agglutination as seen in the electron microscope. (D) Virology, 16, 84-90. 
Kapikian, A. Z., Almeida, J. D., and Scott, E. J. (1972). Immune electronmicroscopy of rhinoviruses, J. Virol., 10, 142-146.

Lafferty, K. J., and Oertelis, S. (1963). The interaction between virus and antibody. III. Examination of virus antibody complexes with the electron microscope. Virology, 21, 91-99.

Rigby, C., and Johnson, C. M. (1972). Immuno-electron microscopy of herpes simplex virus. Canad. J. Microbiol., 18, 1337-1341.

\section{Reports and Bulletins prepared by the Association of Clinical Biochemists}

The following reports and bulletins are published by the Association of Clinical Biochemists. They may be obtained from The Administrative Office, Association of Clinical Biochemists, 7 Warwick Court, Holborn, London, WC1R 5DP. The prices include postage, but air mail will be charged extra. Overseas readers should remit by British Postal or Money Order. If this is not possible the equivalent of 50p is the minimum amount that can be accepted.

SCIENTIFIC REPORTS

3 Automatic Dispensing Pipettes. An assessment of 35 commercial instruments 1967 P. M. G. BROUGHTON, A. H. GOWENLOCK, G. M. WIDDOWSON, and K. A. AHLQUIST $80 \mathrm{p}(\$ 2)$

4 An Evaluation of five Commercial Flame Photometers suitable for the Simultaneous Determination of Sodium and Potassium March 1970 P. M. G. BROUGHTON and J. B. DAWSON $80 p(\$ 2)$

\section{SCIENTIFIC REVIEWS}

1 The Assessment of Thyroid Function March 1971 F. V. FLYNN and J. R. HOBBS 60p (\$1.50)

2 Renal Function Tests Suitable for Clinical Practice January 1972 F. L. MTCHELL, N. VEALL, and R. W. E. WATTS $60 \mathrm{p}(\$ 1.50)$

\section{TECHNICAL BULLETINS}

9 Determination of Urea by AutoAnalyzer November 1966 RUTH M. HASLAM 40p (\$1)

11 Determination of Serum Albumin by AutoAnalyzer using Bromocresol Green October 1967 B. E. NORTHAM and G. M. WIDDOWSON 40p (\$1)

13 An Assessment of the Technicon Type II Sampler Unit March 1968 B. C. GRAY and G. K. MCGOWAN 40p (\$1)

14 Atomic Absorption Spectroscopy. An outline of its principles and a guide to the selection of instruments May 1968 J. B. DAWSON and P. M. G. BROUGHTON 40p (\$1)

15 A Guide to Automatic Pipettes (2nd edition) June 1968 P. M. G. BROUGHTON 40p (\$1)

16 A Guide to Automation in Clinical Chemistry May 1969 P. M. G. BROUGHTON 60p (\$1.50)

17 Flame Photometers (2nd edition) 1969 P. WILDING $60 \mathrm{p}(\$ 1.50)$
19 Spectrophotometers. A comparative list of low-priced instruments readily available in Britain May 1970 C. E. WILDE and P. SEWELL 60p (\$1.50)

20 Quantities and Units in Clinical Biochemistry June 1970 P. M. G. BRoughtoN 60p (\$1.50) More than 30 copies in units of 10 at 20 p

21 Filter Fluorimeters: A comparative list of 18 instruments September 1970 H. BRAUNSBERG and s. $s$. BROWN 60p (\$1.50)

22 Bilirubin standards and the Determination of Bilirubin by Manual and Technicon AutoAnalyzer Methods January 1971 BARBARA BILLING, RUTH HASLAM, and N. WALD $60 \mathrm{p}(\$ 1.50)$

23 Interchangeable Cells for Spectrophotometers and Fluorimeters September 1971 E. S. BROWN and A. H. GOWENLOCK 60p (\$1.50)

24 Simple Tests to Detect Poisons March 1972 B. W. MEADE et al. $60 \mathrm{p}(\$ 1.50)$

25 Blood Gas Analysers May 1972 K. DIXON 60p $(\$ 1.50)$

26 Kits for Enzyme Activity Determination September 1972 S. B. ROSALKI and D. TARLOW 80p (\$2.00)

27 Assessment of Pumps Suitable for Incorporation into Existing Continuous Flow Analytical Systems November 1972 A. FLECK et al. 60p (\$1.50)

28 Routine Clinical Measurements of Transferrin in Human Serum September 1973 K. DIXON 60p (\$1.50)

29 Control Materials for Clinical Biochemistry (5th edition) September 1973 J. F. STEVENS 60p (\$1.50)

30 Notes on the Quality of Performance of Serum Cholesterol Assays September 1973 s. s. BROWN 60p (\$1.50) 